\title{
EFIKASI ASAP CAIR KAYU LABAN (Vitex pubescens) PADA SUHU PROSES PRODUKSI DAN KONSENTRASI BERBEDA TERHADAP JAMUR Ophiostoma piliferum
}

\author{
Efficacy of Laban (Vitex Pubescens) Wood Vinegar from Different Production Process \\ Temperature and Concentration Against Ophiostoma piliferum
}

\section{H. A. Oramahi*, Farah Diba, Nurhaida, Wahdina, Dina Setyawati, dan M. Dirhamsyah Fakutas Kehutanan, Universitas Tanjungpura,}

Alamat korespondensi: oramahi_stp@yahoo.com

\begin{abstract}
ABSTRAK
Efikasi asap cair hasil pirolisis dari kayu laban (Vitex pubescens) terhadap Ophiostoma piliferum telah dilakukan. Penelitian ini bertujuan mengevaluasi kemampuan asap cair sebagai antijamur (O. piliferum) secara in vitro. Asap cair yang digunakan diperoleh dengan cara pirolisis pada suhu produksi asap cair dan konsentrasi asap cair yang berbeda. Efikasi asap cair terhadap jamur dilakukan pada media PDA (Potato Dextrose Agar) dalam cawan Petri dengan campuran asap cair pada konsentrasi 0, 0,5, 1,5, dan 2,0 (v/v). Pengujian aktivitas antijamur dilakukan menggunakan rancangan acak lengkap tipe faktorial. Data yang diperoleh dianalisis dengan sidik ragam. Pengaruh antarperlakuan dilakukan uji beda nyata jujur (BNJ) pada taraf nyata $5 \%$. Analisis data menggunakan SAS versi 9.13. Hasil penelitian menunjukkan bahwa suhu pirolisis produksi asap cair dan konsentrasi asap cair berpengaruh terhadap daya penghambatan pertumbuhan jamur. Makin tinggi suhu pirolisis produksi asap cair dan konsentrasinya dan makin tinggi daya penghambatan terhadap pertumbuhan jamur, O. piliferum.
\end{abstract}

Kata kunci: daya hambat pertumbuhan jamur, kayu laban, asap cair

\section{ABSTRACT}

Efficacy wood vinegar produced from wood laban (Vitex pubescens) against Ophiostoma piliferum fungus was evaluated. The objectives of this research to perform in vitro antifungal of wood vinegar from laban wood against $\mathrm{O}$. piliferum. The source of lignocelluloses biomass was the carbonization process used three temperature i.e. 350, 400 and $450^{\circ} \mathrm{C}$. Efficacy of wood vinegar to the fungus carried on PDA (potato dextrose agar) in a Petri dish that has been mixed with the wood vinegar with a concentration of $0,0.5,1.0,1.5$, and $2.0 \%(v / v)$. The antifungal test was a factorial 3 by 5 in a completely randomized design. The means were separated using Tukey's test at $p=0.05$. All data were analyzed using the SAS software (version 8.2, SAS Institute Inc., NC. USA). The test results showed that the pyrolysis temperature effect and concentration of wood vinegar on the inhibition of fungal growth. The higher pyrolysis temperature and concentration, the inhibition of fungal growth was increased.

Keywords: inhibition of fungal growth, laban wood, wood vinegar

\section{PENDAHULUAN}

Jamur (fungi) merupakan organisme yang dapat merusak tanaman mulai dari benih, tanaman di persemian bahkan sampai pascapanen. Tanaman sebagai produk akhirnya berupa kayu, jamur menyerang saat tanaman di pembibitan sampai pemanenan kayu. Sebagai contoh, jamur Ophiostoma huntii menyerang tanaman Pinus radiate pada saat pembibitan (Reay et al. 2002). Kim et al. (2005) melaporkan bahwa kayu pinus berupa log juga terserang oleh jamur marga Ophiostoma, seperti Ophiostoma floccosum, O. huntii, O. nigrocarpum $O$. piceae, $O$. piliferum, $O$. quercus dan $O$. radiaticola. Heiniger et al. (2011) menyatakan bahwa hasil isolasi dari ranting 
dan cabang tanaman pinus dominan ditumbuhi oleh jamur Ophiostoma sp. Jamur O. piliferum (sapstaining fungus) salah satu jamur yang menyerang tanaman pinus mulai dari bagian daun, ranting, cabang sampai bagian kayu setelah tanaman ditebang/panen (Thwaites et al. 2005).

Dampak dari serangan jamur $O$. piliferum adalah menurunkan nilai ekonomi kayu yang sudah dipanen. Usaha yang dilakukan untuk mengurangi dampak yang ditimbulkan akibar serangan jamur ini adalah pengendalian dengan menggunakan bahan kimia sintetis. Namun pengendalian jamur menggunakan bahan kimia sintetis dapat menimbulkan kerugian antara lain adanya residu, dampak terhadap lingkungan dan manusia (Grewal et al. 2018; Thomasson et al. 2015). Alternatif tindakan yang dilakukan untuk mengurangi dampak tersebut adalah pengendalian jamur menggunakan bahan alami yang mampu mengurangi pertumbuhan jamur, salah satunya adalah asap cair. Beberapa peneliti telah melakukan penelitian tentang produksi asap cair dari berbagai kayu seperti nyamplung (Wibowo, 2012), gelam (Alpian et al. 2014) dan non kayu seperti bambu (Sangsuk et al. 2018) dan cangkang pala (Lala et al. 2017).

Pemanfaatan asap cair yang sudah dilakukan antara lain sebagai bahan antirayap (Adfa et al. 2017), antibakteri (Rusli et al. 2016), antijamur (Oramahi et al. 2011; Theapparat et al. 2015). Adfa et al. (2017) menyatakan bahwa asap cair dari Toonia sinensis yang mengandung asam asetat berfungsi sebagai antirayap terhadap rayap Coptotermes curvignathus Holmgren. Rusli et al. (2016) menemukan bahwa pupuk organik dan asap cair mampu mengendalikan Xanthomonas oryzae pv. oryzae penyebab penyakit kresek dan Pyricularia grisea penyebab penyakit blas pada padi. Theapparat et al. (2015) melaporkan bahwa lima jenis asap cair dari Eucalyptus camaldulensis, Leucaena leucocephala, Azadirachta indica, Hevea brasiliensis (kayu karet), dan Dendrocalamus asper (bambu) mempunyai daya penghambatan terhadap jamur pelapuk putih, jamur pelapuk cokelat dan saptain fungus. Pangestu et al. (2015) melaporkan bahwa hasil pirolisis tempurung kelapa mempuyai aktivitas sebagai fungisida dalam menghambat pertumbuhan jamur Phytophthora sp. penyebab penyakit busuk buah kakao sebesar 76,80\% pada kosentrasi 0,34\%.

Pemanfaatan asap cair dalam menghambat pertumbuhan jamur sangat dipengaruhi oleh jumlah kandungan (konsentrasi) komponen penyusun asap cair. Komponen penyusun asap cair dipengaruhi oleh salah satu faktor yaitu suhu pirolisis. Perbedaan jumlah kandungan asap cair seperti asam organik dan fenol serta turunan fenol diduga sangat 
mempengaruhi kemampuan asap cair sebagai antijamur. Gao et al. (2020) mengungkapkan bahwa hasil identifikasi menggunakan GC-MS terhadap asap cair yang diperoleh dari jerami gandum mempunyai 51 komponen terdiri atas fenol, keton, alkohol, piridin, ester dan komponen asam. Di antara 51 komponen tersebut, komponen utama penyusun asap cair dari jerami gandum adalah o-kresol, asam asetat, 4-etil fenol, 3-methylcatechol dan asam propionat. Wibowo (2012) melaporkan bahwa aap cair dari nyamplung mengandung senyawa kimia antara lain fenol, karbonil dan asam organic seperti asam asetat, asam butanoat, asam malonate, dan keton serta alkil aril eter. Perbedaan jenis asap cair dan kandungan kimia ini yang mengakibatkan adanya perbedaan sifat antijamur.

Salah satu bahan baku pembuatan asap cair berasal dari tanaman laban (batang kayu). Tanaman laban merupakan jenis pohon dari keluarga Lamiaceae, genus Vitex dan spesis Vitex pubescens Vahl. Tanaman laban mampu menginvasi padang rumput yang didominasi oleh Imperata cylindrica di Kalimantan Barat. Tanaman ini cepat tumbuh setelah dilakukan pembakaran terhadap alang-alang (Utama et al. 1999)

Berdasarkan hal tersebut, penelitian pembuatan asap cair dari kayu laban pada suhu pirolisis 350,400 , dan $450{ }^{\circ} \mathrm{C}$ dan mengevaluasi sifat antijamur asap cair terhadap jamur Ophiostoma piliferum perlu dilakukan. Tujuan penelitian ini adalah untuk mengevaluasi daya hambat asap cair terhadap jamur, O. piliferum. Jamur ini berdampak terhadap tanaman pada masa pembibitan sampai pemanenan tanaman.

\section{METODE PENELITIAN}

Asap cair yang digunakan hasil pirolisis pada suhu proses produksi yaitu 350, 400, dan $450{ }^{\circ} \mathrm{C}$ dan diperoleh dari penelitian sebelumnya (Oramahi dan Yoshimura, 2013). Isolat jamur $O$. piliferum diperoleh dari Jurusan Forest Biology \& Wood Protection Technology, Forestry Faculty, Istanbul University. Turkey. Isolat jamur $O$. piliferum diperbanyak menggunakan media PDA.

Pengujian asap cair terhadap jamur Ophiostoma piliferum dilakukan di Laboratory of Innovative and HumanoHabitability, Kyoto University. Pengujian antijamur asap cair mengacu metode Kartal et al. (2011). Media pertumbuhan jamur menggunakan PDA dalam cawan Petri dengan perlakuan suhu dan kosentrasi asap cair yang berbeda. Suhu pirolisis terdiri atas 350,400 , dan $450{ }^{\circ} \mathrm{C}$ dengan konsentrasi asap cair yaitu $0,0.5,1.0,1.5$, dan $2.0 \%$. Medium PDA dengan campuran berbagai konsentrasi asap cair dan medium PDA sebagai kontrol dilakukan pensterilan menggunakan autoclave pada suhu $121^{\circ} \mathrm{C}$, 
tekanan $103.4 \mathrm{kPa}$ (15 psi) selama 15 menit. Medium PDA dituangkan ke dalam Petri sebanyak $10 \mathrm{~mL}$. Isolat jamur (5 mm) ditumbuhkan tepat ditengah cawan Petri (berisi media PDA). Selanjutkan, cawan Petri berisi media PDA saja digunakan sebagai kontrol. Masing-masing percobaan (control dan perlakuan) diulang sebanyak 4 kali. Cawan Petri yang sudah diinokulasi jamur diinkubasi pada suhu $27{ }^{\circ} \mathrm{C}$. Koloni jamur dihitung diamaternya setelah ada koloni yang tumbuh menutupi semua cawan Petri (7 hari). Daya penghambatan pertumbuhan jamur dihitung dengan menggunakan rumus:

$$
\mathrm{I}=[(\mathrm{C}-\mathrm{T}) / \mathrm{C}] \times 100(\%)
$$

Dimana:

I = persentase penghambatan jamur

$\mathrm{C}=$ diameter pertumbuhan jamur $(\mathrm{mm})$ pada kontrol

$\mathrm{T}=$ diameter pertumbuhan jamur $(\mathrm{mm})$ pada perlakuan asap cair

Rancangan yang digunakan dalam rangka mengevaluasi pengaruh suhu proses produksi asap cair dan konsentrasi asap cair terhadap penghambatan pertumbuhan jamur adalah rancangan acak lengkap tipe faktorial. Faktor pertama yaitu suhu pirolisis produksi asap cair kayu laban terdiri atas 350,400 , dan $450{ }^{\circ} \mathrm{C}$. Faktor kedua adalah konsentrasi asap cair terdiri atas $0,0,5,1,0,1,5$, dan 2,0 \%. Data daya hambat pertumbuhan jamur dianalisis menggunakan sidik ragam. Bila ada perbedaan antarperlakuan dilakukan uji beda nyata jujur (BNJ) pada taraf nyata $5 \%$. Analisis data menggunakan SAS versi 9.13. Analisis regresi linier sederhana dilakukan untuk menentukan pengaruh konsentrasi asap cair dari kayu laban, terdiri atas $0,0,5,1,0,1,5$, dan 2,0 \% (X) terhadap daya hambat pertumbuhan jamur, Ophiostoma piliferum (Y), pada masingmasing suhu proses produksi asap cair kayu laban $\left(350,400\right.$ dan $\left.450{ }^{\circ} \mathrm{C}\right)$. Persamaan regresi sederhana yaitu:

$$
Y=b_{0}+b X
$$

Dimana:

$\mathrm{Y}=$ daya hambat pertumbuhan jamur, $O$. piliferum, $(\%)$,

$b_{0}=$ konstanta

$b=$ koefisien regresi

$\mathrm{X}=$ konsentrasi asap cair kayu laban dalam $\%$.

Data daya hambat yang diperoleh selanjutnya dianalisis dengan regresi linear sederhana untuk mengevaluasi antara variabel $\mathrm{X}$ dan $\mathrm{Y}$ (taraf nyata 5\%) dengan menggunakan SPSS versi 22.

\section{HASIL DAN PEMBAHASAN}

Daya hambat asap cair terhadap pertumbuhan jamur, O. piliferum pada suhu proses produksi asap cair $(350,400$, dan $\left.450{ }^{\circ} \mathrm{C}\right)$ dan konsentrasi asap cair $(0,0,5$, 1,0, 1,5, dan 2,0\%), disajikan pada Tabel 1 .

Tabel 1 menunjukkan bahwa makin tinggi suhu proses produksi asap cair dan 
konsentrasi asap cair kayu laban, makin tinggi daya hambat pertumbuhan jamur, $O$. piliferum. Aplikasi asap cair pada suhu proses produksi $450{ }^{\circ} \mathrm{C}$ dengan konsentrasi asap cair 1,5 dan 2,0\%, daya hambat pertumbuhan jamur, $O$. piliferum berturut turut sebesar 82,78 dan $100 \%$. Efikasi asap cair kayu laban terhadap pertumbuhan jamur, Ophiostoma piliferum pada konsentrasi $0,0,5,1,0$, dan $1,5 \%$ dan masing-masing suhu pirolisis produksi asap cair $\left(350,400\right.$ dan $\left.450{ }^{\circ} \mathrm{C}\right)$, tercantum pada Gambar 1, 2 dan 3.

Persamaan regresi sederhana yang mengekspresikan antara konsentrasi asap cair kayu laban terhadap daya hambat pertumbuhan jamur, O. piliferum pada suhu proses produksi asap cair $(350,400$, dan $450{ }^{\circ} \mathrm{C}$ ) berturut-turut adalah $Y=1,19+$ $0,06_{\mathrm{x}}, \quad Y=1,27+0,04_{\mathrm{x}}$, dan $Y=1,55+$ $0,04_{x}$. Koefisien determinasi perlakuan suhu proses produksi asap cair $(350,400$, dan $450^{\circ} \mathrm{C}$ ), berturut turut adalah $0,90,0,98$, dan 0,92 . Tingginya koefisien determinasi proses produksi asap cair pada suhu 350, 400, dan $450^{\circ} \mathrm{C}$ membuktikan bahwa konsentrasi asap cair signifikan dalam menghambat pertumbuhan jamur, $O$. piliferum. Gambar 1-3 mengekspresikan bahwa semakin tinggi konsentrasi asap cair

Tabel 1. Daya hambat asap cair kayu laban terhadap jamur, Ophiostoma piliferum pada suhu proses produksi asap cair dan konsentrasi asap cair yang berbeda

\begin{tabular}{|c|c|c|}
\hline \multicolumn{2}{|c|}{ Perlakuan } & \multirow{2}{*}{$\begin{array}{l}\text { Daya Hambat }(\% \\
\text { Jamur Ophiostoma pili }\end{array}$} \\
\hline Asap Cair & Konsentrasi (\%) & \\
\hline \multicolumn{3}{|l|}{ Kontrol } \\
\hline \multirow[t]{5}{*}{ A1 } & 0,0 & $0 \pm 0 \mathrm{a}$ \\
\hline & 0,5 & $18,34 \pm 2,64 b$ \\
\hline & 1,0 & $28,33 \pm 6,39 \mathrm{bc}$ \\
\hline & 1,5 & $37,50 \pm 4,83 \mathrm{cde}$ \\
\hline & 2,0 & $67,50 \pm 17,03 \mathrm{~g}$ \\
\hline \multirow[t]{4}{*}{$\mathrm{A} 2$} & 0,5 & $18,64 \pm 3,55 b$ \\
\hline & 1,0 & $38,89 \pm 3,85 \mathrm{de}$ \\
\hline & 1,5 & $56,95 \pm 1,90 \mathrm{fg}$ \\
\hline & 2,0 & $100 \pm 0 \mathrm{~h}$ \\
\hline \multirow[t]{4}{*}{ A3 } & 0,5 & $26.12 \pm 111 b c$ \\
\hline & 1,0 & $43.05 \pm 2.63 \mathrm{ef}$ \\
\hline & 1,5 & $82.78 \pm 19.88 \mathrm{~h}$ \\
\hline & 2,0 & $100 \pm 0.00 \mathrm{fh}$ \\
\hline
\end{tabular}

Keterangan: A1 : asap cair produksi pada suhu pirolisis $350^{\circ} \mathrm{C}, \mathrm{A} 2$ : asap cair produksi pada suhu pirolisis $400{ }^{\circ} \mathrm{C}, \mathrm{A} 3$ : asap cair produksi pada suhu pirolisis $450{ }^{\circ} \mathrm{C}$, 'Ratarata $(n=4)$. Angka yang diikuti oleh huruf yang sama pada kolom yang sama tidak berbeda nyata $(P<0.05)$ berdasarkan uji BNJ. 


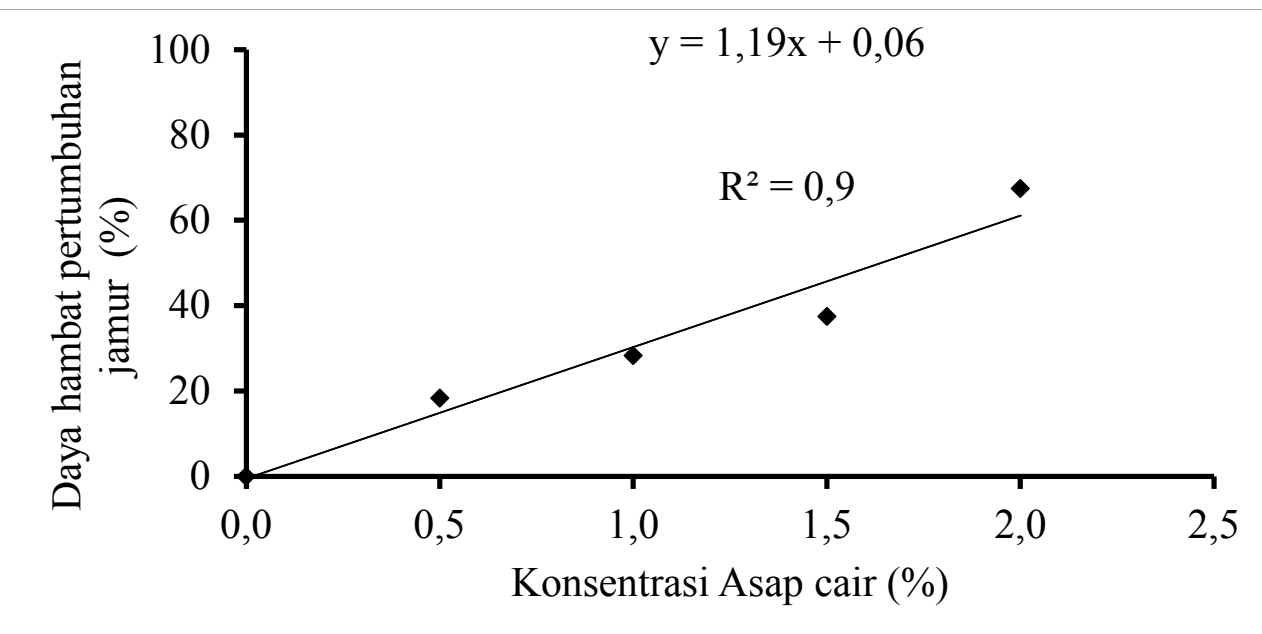

Gambar 1. Hubungan antara konsentrasi asap cair kayu laban (\%) terhadap daya hambat pertumbuhan jamur, Ophiostoma piliferum pada suhu $350{ }^{\circ} \mathrm{C}$.

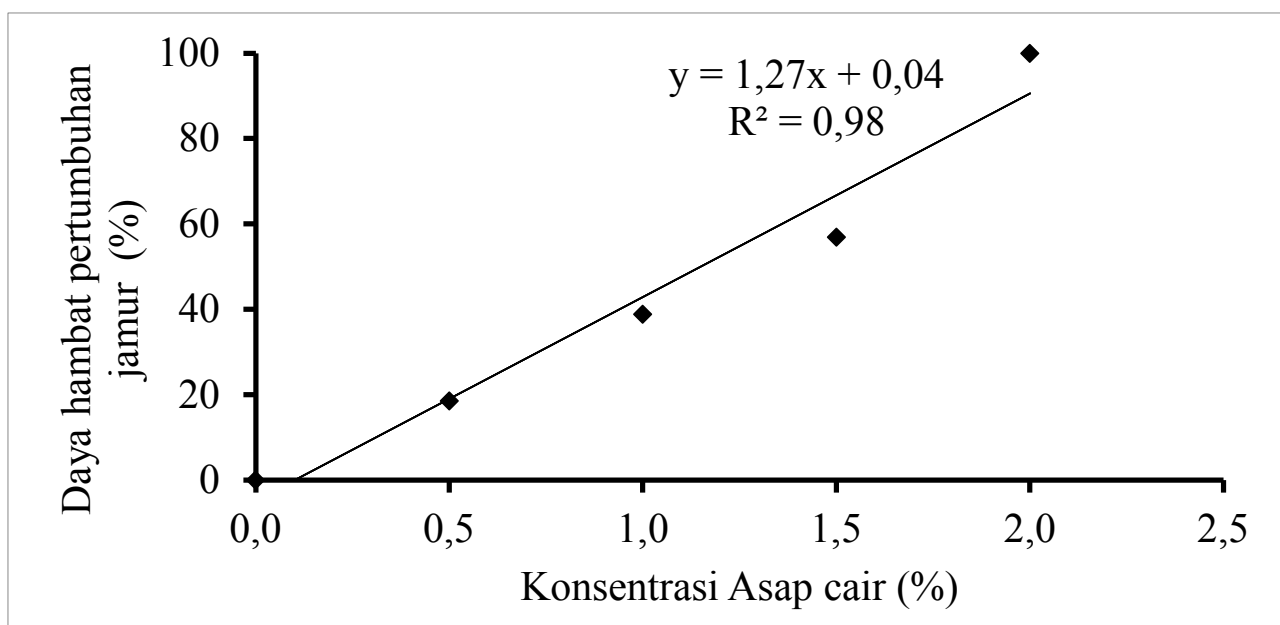

Gambar 2. Hubungan antara konsentrasi asap cair kayu laban (\%) terhadap daya hambat pertumbuhan jamur, Ophiostoma piliferum pada suhu $400{ }^{\circ} \mathrm{C}$.

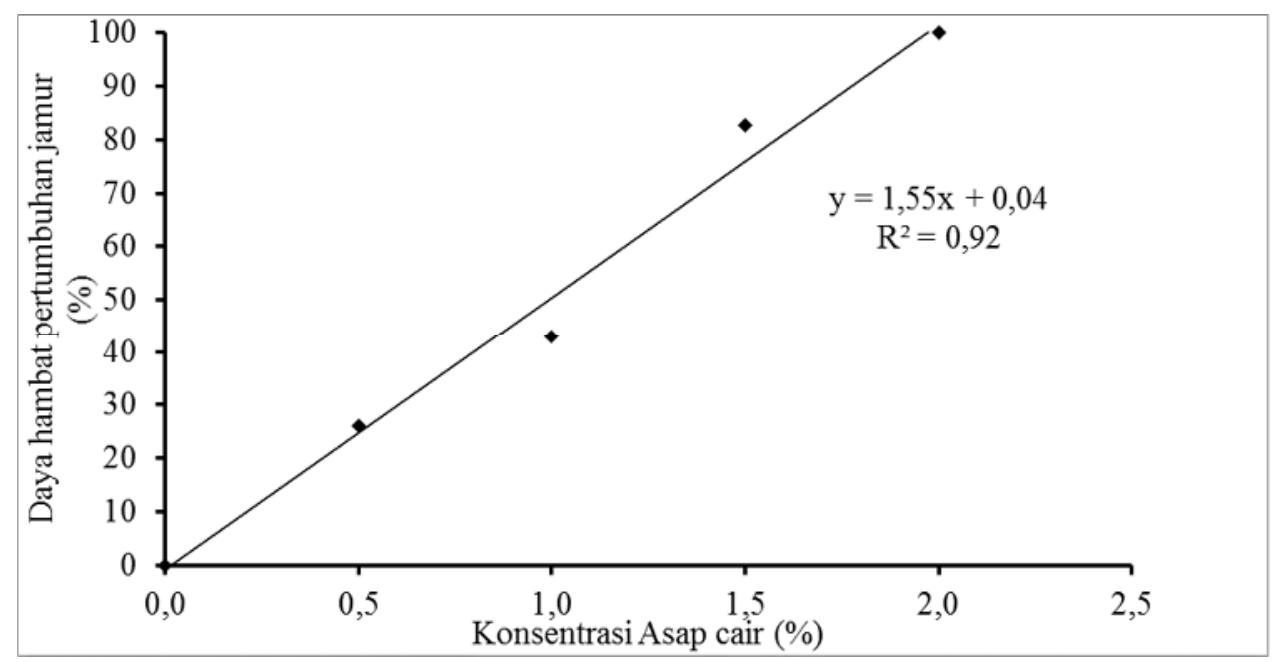

Gambar 3. Hubungan antara konsentrasi asap cair kayu laban (\%) terhadap daya hambat pertumbuhan jamur, Ophiostoma piliferum pada suhu $450{ }^{\circ} \mathrm{C}$. 
kayu laban semakin tinggi daya hambat asap cair tersebut terhadap pertumbuhan jamur, O. piliferum pada suhu 350, 400 dan $450{ }^{\circ} \mathrm{C}$. Hal ini menjelaskan bahwa makin tinggi konsentrasi asap cair, makin tinggi komponen kimia penyusun asap cair yang sekaligus berdampak terhadap sifat antijamur.

Hasil analisis regresi dan korelasi menunjukkan bahwa perlakuan konsentrasi asap cair kayu laban berpengaruh nyata terhadap daya hambat pertumbuhan jamur, O. piliferum $(p<0,05)$ pada suhu pirolisis 350, 400 dan $450{ }^{\circ} \mathrm{C}$. Hasil studi ini diperkuat oleh penelitian Kartal et al. (2011) dan Oramahi dan Yoshimura (2013). Konsentrasi asap cair makin tinggi sebagai titik kritis dalam rangka menghambat pertumbuhan jamur (Kartal et al. 2011).

Faktor suhu pirolisis asap cair sangat berpengaruh terhadap pertumbuhan jamur, makin tinggi suhu makin tinggi daya penghambatan pertumbuhan jamur. Hal ini membuktikan bahwa komponen kimia dalam asap cair mempengaruhi pertumbuhan jamur. Oramahi dan Yoshimura (2013) melaporkan bahwa kadar asam dalam asap cair yang diperoleh dari kayu laban pada suhu proses produksi $\left(350,400\right.$, dan $\left.450^{\circ} \mathrm{C}\right)$ berturut-turut sebesar 2,13, 2,10, dan 3,27\%. Kandungan asam pada suhu $450{ }^{\circ} \mathrm{C}$ merupakan jumlah komponen tertinggi sejalan dengan daya penghambatan pertumbuhan jamur yang terbesar (Tabel 1). Selain kandungan asam, kadungan fenol juga berpengaruh terhadap pertumbuhan jamur. Hal ini diperkuat oleh Oramahi dan Yoshimura (2013) yang menyatakan bahwa kadar fenol total pada asap cair hasil proses produksi pada suhu $\left(350,400\right.$, dan $\left.450^{\circ} \mathrm{C}\right)$ berturut-turut adalah $5,22,5,89$, dan $5,15 \%$.

Penelitian yang telah dilakukan tersebut hanya menganalisis kadar fenol total belum menganalisis turunan fenol pada masing-masing suhu proses produksi asap cair 350,400 , dan $450^{\circ} \mathrm{C}$. Hal ini didukung oleh penelitian Wu et al. (2015), yang menyatakan komponen kimia asap cair bambu tertinggi adalah asam dan fenol. Senyawa fenol berasal dari hasil degradasi senyawa lignin yang ada pada kayu (Theapparat et al. 2015). Penelitian lebih lanjut perlu dilakukan untuk mengevaluasi kandungan senyawa turunan fenol yang sangat berpengaruh terhadap pertumbuhan jamur. Ma et al. (2011) menyatakan bahwa asap cair mengandung komponen asam organik yang tinggi menyebabkan terjadinya peningkatan kemampuan sebagai antimikrobia, sedangkan asap cair mengandung fenol yang tinggi meyebabkan terjadinya peningkatan sebagai antioksidan. Gao et al. (2020) menyatakan bahwa asap cair dari jerami gandum menunjukan aktivitas yang kuat dalam menghambat pertumbuhan jamur Fusarium graminearum. Komponen kimiawi dalam 
asap cair yang berfungsi sebagai antijamur antara lain 2-etil fenol dan 4-etil fenol. Hal ini diperkuat oleh Zabka dan Pavela (2013) yang melaporkan bahwa komponen 2-etil fenol dan 4-etil fenol mempunyai kemapuan dalam menghamat pertumbuhan jamur dari genus Fusarium, Penicillium dan Aspergillus.

Penelitian sebelumnya mengungkapkan bahwa perbedaan suhu pirolisis dan bahan baku pembuatan asap cair menyebabkan perbedaan konsentrasi dan jumlah komponen yang ada dalam asap cair. Sebagai contoh Mathew et al. (2015) melaporkan bahwa komponen kimia asap cair hasil pirolisis tanaman nenas, antara lain fenol (69,50\%), alkil aril eter (9,33\%), keton $(7,76 \%)$, turunan furan dan firan $(3,57 \%)$, asam organik $(2,67 \%)$, aldehid $(1,05 \%)$, dan alkohol (0,90\%). Rosalina et al. (2016) melaporkan bahwa asap cair yang diperoleh dari kayu bintaro (Cerbera odollam GAERTN) mempunyai komponen dominan yaitu asam asetat, fenol, 2-metoksi fenol, 2-metoksi 4 metil fenol, asam 9oktadekonoid dan 2,3 dihidroksipropil ester.

\section{KESIMPULAN}

Asap cair kayu laban mempunyai aktivitas dalam menghambat pertumbuhan jamur Ophiostoma piliferum. Semakin tinggi suhu pirolisis produksi asap cair dan konsentrasi dan asap cair, semakin tinggi daya hambat pertumbuhan jamur. Asap cair yang mempunyai daya penghambatan pertumbuhan jamur terbesar diperoleh pada suhu proses produksi $450^{\circ} \mathrm{C}$.

\section{UCAPAN TERIMA KASIH}

Penulis mengucapkan terima kasih kepada Prof. Dr. Tsuyoshi Yoshimura yang telah memberikan fasilitas di Laboratorium, dan Prof. Dr. Nami Kartal yang telah memberikan bantuan isolat jamur Ophiostoma piliferum dan pustaka berupa artikel di jurnal internasional.

\section{DAFTAR PUSTAKA}

Adfa, M., A.J. Kusnanda, W.D. Saputra, C. Banon, M. Efdi, and M. Koketsu. 2017. Termiticidal activity of toona sinensis wood vinegar against Coptotermes curvignathus Holmgren. Rasayan Journal of Chemistry, 10: 1088-1093.

Alpian, A., T.A. Prayitno, J.P.G. Sutapa, dan B. Budiadi. 2014. Kualitas asap cair batang gelam (Melaleuca sp.). Jurnal Penelitian Hasil Hutan, 32: 83-92.

Gao, T., R. Bian, S. Joseph, S. Taherymoosavi, D.R. Mitchell, P. Munroe, J. Xu and J. Shi. 2020. Wheat straw vinegar: A more costeffective solution than chemical fungicides for sustainable wheat plant protection. Science of The Total Environment (in press).

Grewal, A., L. Abbey and L.R. Gunupuru. 2018. Production, prospects and potential application of pyroligneous acid in agriculture. Journal of Analytical and Applied Pyrolysis, 135: 152-159. 
Heiniger, U., F. Theile, A. Rigling and D. Rigling. 2011. Blue-stain infections in roots, stems and branches of declining Pinus sylvestris trees in a dry inner alpine valley in Switzerland. Forest Pathology, 41: 501-509.

Kartal, S.N., E. Terzi, C. Kose, J. Hofmeyr and Y. Imamura. 2011. Efficacy of tar oil recovered during slow pyrolysis of macadamia nut shells. International Biodeterioration \& Biodegradation, 65: 369-373.

Kim, G.H., J.J. Kim, Y.W. Lim and C. Breuil. 2005. Ophiostomatoid fungi isolated from Pinus radiata logs imported from New Zealand to Korea. Canadian Journal of Botany, 83: 272-278.

Lala, N.S., J. Pongoh and N. Taher. 2017. Penggunaan asap cair cangkang pala (Myristica fragrans) sebagai bahan pengawet pada pengolahan ikan tongkol (Euthinnus affinis) asap. Media Teknologi Hasil Perikanan, 5: 24-29.

Ma, X., Q. Wei, S. Zhang, L. Shi and Z. Zhao. 2011. Isolation and bioactivities of organic acids and phenols from walnut shell pyroligneous acid. Journal of Analytical and Applied Pyrolysis, 91: 338-343.

Mathew, S., Z.A. Zakaria and N.F. Musa. 2015. Antioxidant property and chemical profile of pyroligneous acid from pineapple plant waste biomass. Process Biochemistry, 50: 19851992.

Oramahi, H. A., F. Diba, dan Wahdina. 2011. Aktivitas anti jamur asap cair dari serbuk gergaji kayu akasia (Acacia mangium Willd) dan kayu laban (Vitex pubescens Vahl). Bionatura, 13(1): 79-84.

Oramahi, H.A. and T. Yoshimura. 2013. Antifungal and antitermitic activities of wood vinegar from Vitex
Pubescens Vahl. Journal of Wood Science, 59: 344-350

Pangestu, E., I. Suswanto dan S. Supriyanto. 2015. Uji penggunaan asap cair tempurung kelapa dalam pengendalian Phytophthora sp. penyebab penyakit busuk buah kakao secara in vitro. Perkebunan dan Lahan Tropika, 4: 39-44.

Reay, S.D., P.J. Walsh, A. Ram, and R.L. Farrell. 2002. The invasion of Pinus radiata seedlings by sapstain fungi, following attack by the Black Pine Bark Beetle, Hylastes ater (Coleoptera: Scolytidae). Forest Ecology and Management, 165: 4756.

Rosalina, T.T., E. Riani, and S. Sugiarti. 2016. An environmental friendly pesticide from bintaro (Cerbera odollam gaertn) liquid smoke for pine wood preservation against a subterranean termite Captotermes curvignathus HOLMGREN attack. Rasayan Journal of Chemistry, 9: 438-443

Rusli, I.K., L. Soesanto dan R.F. Rahayuniati. 2016. Pengaruh Pupuk Organik Cair dan Asap Cair dalam Pengendalian Xanthomonas oryzae pv. oryzae dan Pyricularia grisea pada Padi Gogo Galur G136. Jurnal Perlindungan

Tanaman Indonesia, 20: 95-100.

Sangsuk, S., S. Suebsiri and P. Puakhom. 2018. The metal kiln with heat distribution pipes for high quality charcoal and wood vinegar production. Energy for Sustainable Development, 47: 149-157.

Theapparat, Y., A. Chandumpai, W. Leelasuphakul and N. Laemsak. 2015. Pyroligneous acids from carbonisation of wood and bamboo: their components and antifungal activity. Journal of Tropical Forest Science, 27: 517-526. 
Thomasson, G. J., F. Capizzi, J. Dost, J. Morrell and D. Miller. 2015. Wood preservation and wood products treatment. Oregon State University, Oregon, United State of America

Thwaites, J. M., R.L. Farrell, S.M. Duncan, S.D. Reay, R.A. Blanchette, E. Hadar, E. Hadar, T.C. Herrington and D. McNew. 2005. Survey of potential sapstain fungi on Pinus radiata in New Zealand. New Zealand Journal of Botany, 43: 653-663.

Utama R, D. Rantan, W. de Jong, and S. Budhi. 1999. Income generation through rehabilitation of Imperata grasslands: Production of Vitex pubescens as a source of charcoal'. In J.M. Roshetko and D.O. Evans (eds). Domestication of agroforestry trees in Southeast Asia. Forest Farm and
Tree Community Tree Research Reports, Special Issues. Winrock International, Morrilton Arkansas, pp 175-184

Wibowo, S. 2012. Karakteristik asap cair tempurung nyamplung. Jurnal Penelitian Hasil Hutan, 30: 218-227.

Wu, Q., S. Zhang, B. Hou, H. Zheng, W. Deng, D. Liu and W. Tang. 2015. Study on the preparation of wood vinegar from biomass residues by carbonization process. Bioresource Technology, 179: 98-103.

Zabka, M. and R. Pavela. 2013. Antifungal efficacy of some natural phenolic compounds against significant pathogenic and toxinogenic filamentous fungi. Chemosphere, 93: 1051-1056. 